\title{
Effectiveness of an Intervention Regarding Weight Status of Selected New Mexico Kindergarten Children and their Parent’s Perceptions
}

\author{
Amanda Jones and Susan C. Forster-Cox \\ New Mexico State University
}

\begin{abstract}
The purpose of this study was to analyze pre-existing data of selected kindergarten children in New Mexico regarding the relationship between measured body mass index (BMI) and parents/guardians selfreported perceptions of their child's weight status. The study is unique because it gives the opportunity to gauge the effectiveness of an intervention that is tailored to a child's BMI. A total of six districts and 35 schools agreed to participate during this 2004-05 study. A total of 1,480 kindergarten children had their BMI measured by the school nurses. Two instruments were used to conduct the study, a bilingual pre- and post-intervention survey, and the CDC's gender-specific body mass index for age percentile charts. The intervention materials included only literature for the parent/guardian to read. The largest variation in changes of perception occurred in the borderline categories of at risk of overweight and underweight. On the pre-intervention survey, $10 \%$ of the survey respondents accurately described their child as at risk of overweight and increased to $47 \%$ on the post- intervention survey. A total of $11 \%$ of survey respondents accurately described their child's weight status as underweight on the pre- intervention survey and this increased to $23 \%$ on the post-intervention survey. This study was a seminal attempt to obtain information regarding childhood obesity in the state of New Mexico, particularly among kindergarten children. Interventions regarding childhood obesity should be tailored to the parent/guardian as well as the child. Different interventions are needed for parents/guardians of children in the definitive categories of overweight and normal weight than for those parents/guardians of children who are at risk of overweight and underweight.
\end{abstract}

(c) 2007 Californian Journal of Health Promotion. All rights reserved. Keywords: Body Mass Index, Kindergarten, Perception, Overweight

\section{Introduction}

Overweight in children is an epidemic in the U.S., and is threatening children's health. In March 2004, the Centers for Disease Control and Prevention (CDC) released the results of a study conducted regarding preventable deaths. They concluded that poor diet and inactivity are close to overtaking cigarette smoking as the leading causes of preventable death (National Center for Chronic Disease Prevention and Health Promotion [NCCDPHP], CDC, 2004). At this rate, the current generation of U. S. children will not live as long as their parents (Nation Institute for Health Care Management Foundation [NIHCMF], 2004).

The purpose of the present study was to analyze existing data collected by the New Mexico
Department of Health (NMDOH). Prior to the initiation of this study, permission was given by the NMDOH to use data collected in 2004-2005. The purpose of the present study was to analyze existing data collected by the New Mexico Department of Health (NMDOH). Prior to the initiation of this study, permission was given by the NMDOH to use data collected in 2004-2005. Approval for the research protocol was received from the Institutional Review Board at New Mexico State University.

This document will specifically address if intervention materials, which in this case included only literature for the parent/guardian to read, were effective in changing parent/guardian perceptions. Since the U. S. is currently experiencing a problem with 
overweight children and New Mexico has no specific data about the weight issues of their kindergarten children, valuable information is contained within the data that have already been collected.

\section{The Increasing Problem of Overweight and Obesity}

From 1960 to 1980, the prevalence of overweight and obesity among children six to eleven years of age in the U. S. was relatively stable, staying around 5\%. Data from the National Health and Nutrition Examination Survey (NHANES) III, 1988-1994 showed that the prevalence of obesity among children was suddenly increasing, rising to $11 \%$. The most current estimates from NHANES 1999-2002 are that $15.8 \%$ of children ages six to eleven years and $10 \%$ of children two to five years of age are overweight. Therefore the prevalence of overweight among children has tripled over a relatively short period of time (Flegal, 2005; National Center for Health Statistics, [NCHS], 1994; NCHS, 2004).

Almost nine million children, over $15 \%$ of those aged 6-19, were overweight in 2000. This percentage was more than double the prevalence in 1980 for the same age group. The increase in overweight among young children two to five years old was $7 \%$ in 1994 had climbed to $10 \%$ in 2004. Also in 2000, the number of obese people worldwide exceeded the number of underweight people worldwide. If the current trend continues, it is estimated that $40 \%$ of the U.S. population will be obese by 2010 (NIHCMF, 2004; Ogden, 2004; Polk, 2005). This is an alarming trend and raises questions regarding the U. S. medical system, social trends, physical activity, and overall health.

Overweight and obese children and teens are at greater risk for many co-morbid conditions, both immediate and long-term. Compared to normal weight children, the overweight child's risk is approximately 10 times greater for hypertension in young adulthood, three to eight times greater for dyslipidemia, and more than twice as great for diabetes mellitus (Ogden \& Tabek, 2005). Life span is reduced and the risk of diabetes, gall bladder disease, hypertension, heart disease, osteoarthritis, sleep apnea, certain forms of cancer, and sudden death increases. In all actuality, there are few organ systems that overweight and obesity does not affect in childhood (Bray, 2004; Bray \& Bellanger, 2006; Cooney \& Gruber, 2005; Dietz, 1998; Freedman, Dietz, Srinivasan, \& Berenson, 1999; Must \& Strauss, 1999; Polk, 2005).

\section{Preventing Overweight in Children}

Childhood obesity in the U. S. is rising at a disturbing rate. While the underlying causes of the obesity epidemic are plentiful and multifaceted, the main causes have been attributed to the same lifestyle factors as adult obesity. The rapid increase in overweight and obesity are largely due to behavioral and environmental changes in the U. S. Many factors have been suggested as causes of the childhood obesity epidemic including: (a) reduced physical education at school, (b) urban and suburban plans that discourage walking and other physical activities, (c) increased homework loads, (d) campus vending machines, (e) increased television viewing, (f) larger portion sizes, (g) fast-food restaurants, (h) reduced physical activities available during and after school, and (i) television, computers, and video games that replace outdoor leisure time activities (Dietz, 2005; Polk, 2005; Sturm, 2005). Changes in lifestyles seem to be connected to these "causes" of obesity.

\section{How Parent's Knowledge, Attitude, Behaviors, and Beliefs Affect their Child's Weight}

Childhood obesity is a societal phenomenon. It is important to address the obesity issue within the environmental framework of the family (Birch \& Davison, 2001). Overweight in children, as related to the family, seems to be related to a number of variables including: (a) genetic predisposition towards obesity, (b) family perceptions and understanding regarding obesity and health, (c) parent and family lifestyle patterns, including participation in physical and sedentary activities, and (d) family and individual nutritional status (Rich et al., 2005). 
Since parents are influential in a child's behavior, it can be beneficial to educate the parents about specific ways to support their children. This can result in more frequent and long lasting behavior changes. Parents need to be educated so they do not negatively influence their children. A parent needs to know that applying excess control, or failing to offer healthy options, can negatively influence their child and may result in overweight and obesity. Sometimes, if foods are restricted too much, children may desire the foods more, causing similar problems with energy intake, overeating, and overall weight gain as seen when food is not restricted at all. That is, the use of restrictive feeding practices is not effective in limiting children's food intake but can actually encourage consumption of the restricted foods, even in the absence of hunger (Birch \& Davison, 2001; Fisher \& Birch, 2002; McGarvey et al., 2004; Ogden, Flegal, Carroll, \& Johnson, 2002; Ritchie, Welk, Styne, Gerstein, \& Crawford, 2005).

\section{How Effective is Using BMI to Determine a Child's Weight Status?}

The CDC's growth charts were released in 2000 and are recommended for use in clinical practice, research, and to assess size and growth in U. S. children. The CDC's charts include values for Body Mass Index (BMI) percentiles and other anthropometric information. That is, the charts were constructed to include BMI. The child's height, weight, and age can now be plotted on the same chart so the appropriate BMI percentile for that child can be determined. The reference values are based on U.S. national survey data therefore, should only be used for children in the U. S. (as cited in Flegal, Ogden, Wei, Kuczmarski, \& Johnson, 2001; Kuczmarski et al., 2002; Ogden, Carroll, \& Flegal, 2003).

BMI is the recommended measure of relative weight, for both children and adults, and is widely used in clinical settings. It is safe, simple, and inexpensive to obtain. Overall, the correlation between BMI and body composition is accurate. The CDC BMI-for-age charts characterize a U. S. population reference and not a standard of growth for children. All children have similar growth potential, the differences in growth patterns are largely due to environmental and economic constraints. Therefore, the 2000 CDC BMI-for-age growth charts are recommended for screening of overweight and at-risk for overweight in children in the U.S. (Kuzmarski et al., 2002; Ogden, 2004; Ogden et al., 2003; Pietrobelli et al., 1998; as cited in Ressel, 2003; Rubenstein, 2005).

The BMI-for-age chart is recommended for children ages two to five years of age. It is important to mention that, however valuable these charts may be, they do not take into consideration factors like race or ethnicity which may affect the weight status of children. In cases where race and ethnicity are a factor, BMI should be used cautiously. Another issue with the chart is the fact that the distribution of body fat is not taken into account. This would make it possible for a fit individual to be ranked as overweight or obese, according to the chart, because the actual distribution of body fat is not taken into consideration (Daniels, Khoury, \& Morrison, 1997; Dietz \& Bellizzi, 1999; Kuczmarski et al., 2002).

\section{The New Mexico Response}

From November 2004 through March 2005 the $\mathrm{NMDOH}$, Region 5 conducted a study about overweight in children. The purpose of their study was to: (a) determine the BMI of kindergarten children in six school districts in New Mexico, (b) assess the knowledge, attitudes, behaviors, and beliefs regarding nutrition and physical activity of their parents/guardians by using a survey, and (c) educate parents/guardians of kindergarten children about healthy weight and behaviors related to nutrition and physical activity (Mandabach \& Roth-Edwards, 2005).

\section{Theoretical Framework}

The Health Belief Model provides a framework for analyzing the interactions of perceived susceptibility, perceived severity, perceived benefits, perceived barriers, cues to action, and self-efficacy. Since health motivation is the central focus of the model, it is a good fit for addressing problem behaviors that induce health concerns. This model proves useful for the 
present study because the intervention will promote or hinder the perceptions and perceived severity of the child's weight, in the mind of the parent/guardian (Glanz, Rimer \& Lewis, 2002; Rimer \& Glanz, 2005; Rosenstock, 1974).

\section{Methods and Procedures Study Population}

In October 2004, a group of school nurses from across the state of New Mexico wanted to assess the BMI of kindergarten children in the state. The assistance of the epidemiologists from the $\mathrm{NMDOH}$, Public Health Region 5 was requested (known as project team). The assessment was conducted between November 2004 and March 2005 by personnel from the NMDOH, Region 5 . Members of the project team included: the Region 5 epidemiologist, who served as the project leader, the CDC Public Health Prevention Service Fellow, the Region 5 NM School Health Advocate, the Region 5 Dietician, the School nurses from the 35 elementary schools that chose to participate, the New Mexico State University (NMSU) Community Health Interns, the Office of Border Health Interns, and selected NMSU student nurses. The project was funded by the $\mathrm{NMDOH}$, Region 5 (Mandabach \& Roth-Edwards, 2005).

The project team drafted a letter to the Superintendents of selected school districts around New Mexico. The letter was intended to notify the Superintendents of the study and its purpose and request their support. A total of six Districts and 35 schools agreed to participate in the pilot study. The Districts that participated in the study included the Alamogordo, Bloomfield, Clovis, Grants, Hatch, and Los Alamos school districts. The geographic distribution of Districts agreeing to participate in the study was relatively well distributed throughout the entire state as seen in Figure 1.

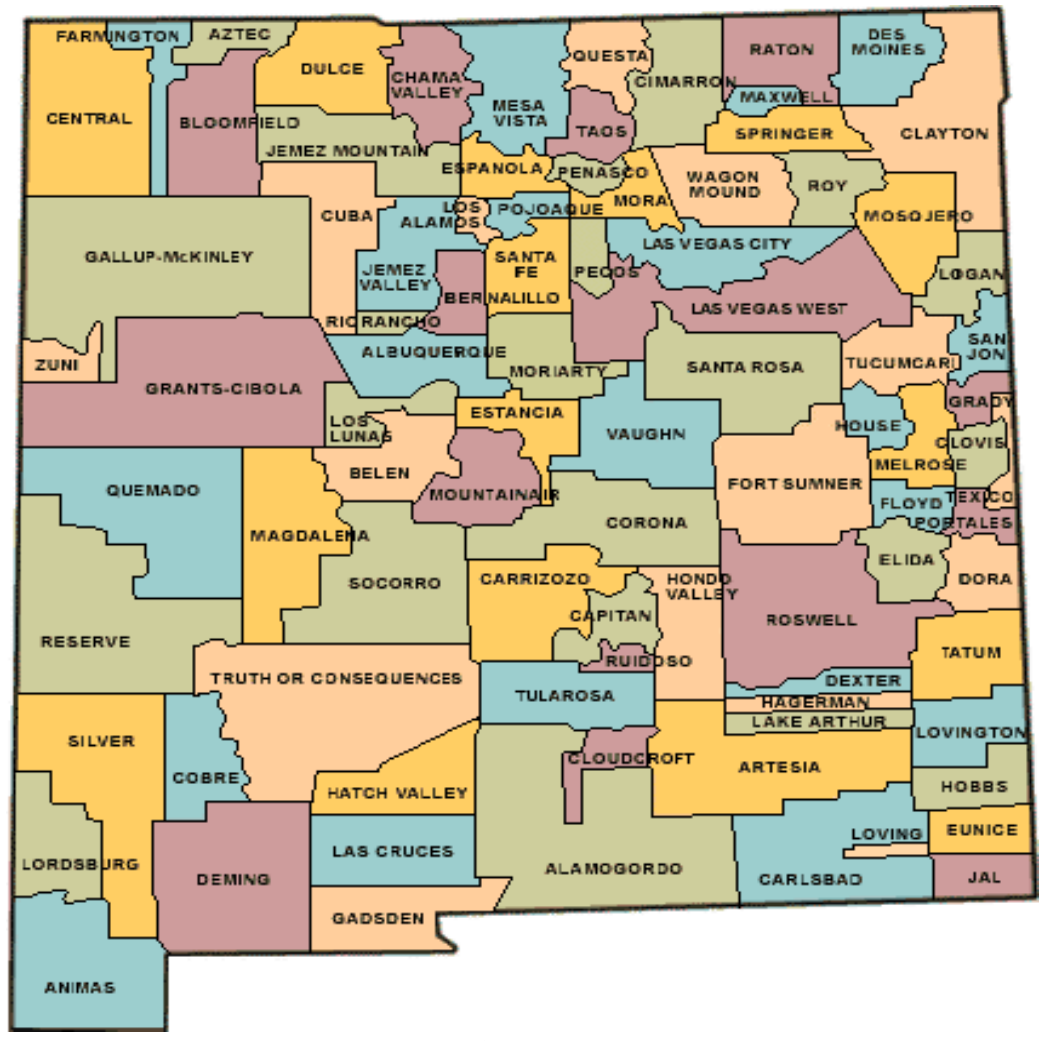

Figure 1

Map of New Mexico by School District.

(New Mexico Public Education Department, 2006) 
In December 2004, a bilingual (English and Spanish) passive consent letter was sent home to every parent/guardian of a kindergarten child enrolled in each of the six districts $(1,613)$. The letters were sent home with the child. If the parent/guardian chose to have their survey responses and their child's BMI included in the study, no action was required with the letter; the parent/guardian responses and child's BMI was automatically included in the study. If the parent/guardian chose to not participate in the study, they were to sign and return the bottom portion of the consent form. Upon receipt of the signed form, the parent/guardian would not be sent a pre- or post-intervention survey and the child would not have their BMI measured. The parent/guardians and their children who chose to participate in the study were also given the option to drop out at any time during the course of the study. This included any cases where the parent/guardian gave consent for the child to have his/her BMI measured but the child chose not to participate during the BMI collection.

\section{Instrumentation}

Two instruments were used to conduct the study, a bilingual pre- and post-intervention survey and the CDC's gender specific body-mass-index for age percentile charts. The charts were specific to the gender of the child.

The pre- and post-intervention survey was created by the project team and is referred to as the parent/guardian perceptions pre-intervention survey and parent/guardian perceptions postintervention survey. The pre-intervention and post-intervention surveys were the same.

The parent/guardian perceptions pre-intervention survey was sent with the child to parents/guardians in a Spanish and English language version. If the English survey was returned, the intervention materials and the postintervention survey were sent in English. If the Spanish version of the pre-intervention survey was returned, the intervention materials and the post-intervention survey were sent in Spanish (Mandabach \& Roth-Edwards, 2005).
The body mass index-for-age percentiles charts allow for the child's percentile to be obtained by plotting the child's age in years to the nearest quarter against the child's BMI. The BMI is obtained by dividing the weight in kilograms over the height in meters squared $\left(\mathrm{kg} / \mathrm{m}^{2}\right)$ or dividing the weight in pounds by the height in inches squared multiplied by 703 (lb/in ${ }^{2}$ x 703). The plotted point will fall either on a percentile line $(5,10,25,50,75,85,90$ or 95$)$ or between two percentile lines allowing for a designation of a percentile range for the child instead of an exact percentile. A percentile below $5 \%$ is considered underweight, $5 \%$ to $84 \%$ is considered normal weight, $85 \%$ to $94 \%$ is considered at risk of overweight, and a percentile of $95 \%$ and greater is considered overweight (CDC, 2005; CDC, 2006).

\section{Data Collection}

Distribution of the pre- and post-intervention survey was done by giving the survey to the school nurses, who distributed them to the teachers, who gave them to the child to take home. In early February 2005 the bilingual parent/guardian pre-intervention survey was sent home with the child to the parents/guardians of kindergarten children enrolled in the study (1535). The refusal rate of the study was $4.8 \%$ (78). Parents/guardians were given two weeks to complete the survey and send it with the child to be given to the school teacher. A total of $46 \%$ (713) of the parents/guardians of kindergarten children enrolled in the study responded to the pre-intervention survey. Surveys were collected by the teachers, given to the school nurse, and mailed to the project leader. The same process was repeated for the post-intervention survey.

A database was created to enter data from the surveys. A code was assigned to each participating child. Student interns completed data entry of the surveys. Once the survey data were entered, data entry was checked and cleaned by a few selected members of the project team. Subsequent entries were systematically compared to the original survey to find any possible errors. The same process was used for the pre- and post-intervention survey databases. 
In February and March 2005, the height and weight of every kindergarten child (1480) present at school on measurement days and enrolled in the study was measured and the child's date of birth and age recorded by the school nurses. The 55 children who did not participate included those who were absent the day BMI's were measured, children who left the school district, or had the refusal of the parent/guardian or child to participate in the BMI collection. School nurses recorded each child's measurements, date of birth, and gender in a Microsoft Excel database. Their databases were then sent to the project team. The project team compiled the BMI data from each school district into one database. The code that was assigned to the child and used on the pre- and post-intervention surveys was also used as the identifier in the BMI database. The BMI data were checked and cleaned in the same manner as the survey data.

Each child's age was calculated and rounded to the nearest quarter of a year using the date of birth and the date of measurement. Using the CDC growth charts (by age and gender), the project team graphed each child's BMI to determine the appropriate percentile for their weight.

In May 2005, the bilingual parent/guardian Postintervention survey was sent home with the child to the parents/guardians of kindergarten children enrolled in the study (1535). Parents/guardians were given two weeks to complete the survey and send it with the child to be given to the school teacher. A total of 39\% (599) of the parents/guardians of kindergarten children enrolled in the study responded to the postintervention survey.

Data were analyzed using Statistical Analysis Software (SAS) 8.0. An analysis could only be conducted on data that contained a BMI result for the child. The differences in the response rate between the pre-intervention survey and the post-intervention survey affected the analysis. Data that had a BMI result and either a preintervention response or a post-intervention response was included in the analysis but only limited information could be obtained. Data that was complete with BMI results, pre-intervention and post-intervention survey responses provided much more detailed information.

\section{Intervention}

From December 2004 through March 2005, student nurses who were a part of the project team researched possible interventions related to overweight and obese children. The student nurses compiled bilingual intervention materials for each weight category. The weight categories included underweight and normal weight, which were given the same intervention, and at risk for overweight and overweight, which were given the same intervention. The materials were edited and approved by the project leader. The intervention for each weight category is presented in Table 1.

In March 2005, an intervention packet was created by the Project team for the child to take home after the pre-intervention survey and before the post-intervention survey was distributed. A packet was given to every household whose child's BMI was measured. The packet contained: 1) a bilingual letter addressed to the parent/guardian that contained the BMI percentiles and weight category of the child; and 2) literature in the form of pamphlets or handouts that were tailored to the results of the child's BMI. The literature was based on the data collected and the bilingual intervention materials that had been gathered by the student nurses (Mandabach \& Roth-Edwards, 2005). The packet was assembled at the $\mathrm{NMDOH}$ District 5 office and was mailed to the school nurses at each participating school. The school nurses gave the packets to the teachers who distributed them to the children to take home.

\section{Data Analysis}

A frequency distribution was done by the project team in May 2005 comparing the pre- and postintervention surveys. General conclusions were drawn from the analysis at that time. The analysis was done using Stata 8.0. The purpose of the present study was to run a more specific analysis on the survey data as well as the results of the BMI calculations. 
Table 1

Intervention by Weight Category

\begin{tabular}{|l|l|l|}
\hline \multicolumn{1}{|c|}{ Weight Category } & \multicolumn{1}{|c|}{ Intervention } & \multicolumn{1}{|c|}{ Source } \\
\hline All Weight Categories & $\begin{array}{l}\text { English and Spanish Version Intervention: } \\
\text { Handout: "10 Steps for Parents: Make } \\
\text { Physical Activity Easy" }\end{array}$ & $\begin{array}{l}\text { U. S. Department of } \\
\text { Agriculture, Food and } \\
\text { Nutrition Service, 2002 }\end{array}$ \\
\hline $\begin{array}{l}\text { Overweight and } \\
\text { At Risk of Overweight }\end{array}$ & $\begin{array}{l}\text { English Intervention: } \\
\text { Publication: "Helping Your Overweight } \\
\text { Child” }\end{array}$ & $\begin{array}{l}\text { National Institute of } \\
\text { Diabetes and Digestive } \\
\text { and Kidney Diseases, } \\
\text { 2004b }\end{array}$ \\
& $\begin{array}{l}\text { Spanish Intervention: } \\
\text { Activity Across You Lifespan: Helping } \\
\text { Your Child" }\end{array}$ & $\begin{array}{l}\text { National Institute of } \\
\text { Diabetes and Digestive } \\
\text { and Kidney Diseases, } \\
\text { 2004a }\end{array}$ \\
\hline $\begin{array}{l}\text { Normal Weight and } \\
\text { Underweight }\end{array}$ & $\begin{array}{l}\text { English and Spanish Version Intervention: } \\
\text { Handout: "Obesity and Children: Helping } \\
\text { your Child Keep a Healthy Weight” }\end{array}$ & $\begin{array}{l}\text { American Academy of } \\
\text { Family Physicians, 2005 }\end{array}$ \\
& \multicolumn{2}{|l}{} \\
\hline
\end{tabular}

\section{Results}

A convenience sample was used with 35 schools in six New Mexico school districts participating. A total of 1,613 parents/guardians and their kindergarten children were asked to participate in the study. Less than $5 \%$ (78) of the original 1,613 chose not to participate in the study, leaving a total of 1,535 parents/guardians and their kindergarten child to be included in the study. BMI was obtained on a total of 1,480 kindergarten children. The pre- and postintervention survey response rates were $47 \%$ (729) and 40\% (616) respectively.

When seeking to learn if the intervention materials, which included only literature for the parent/guardian to read, were effective in changing parent/guardian perceptions, there was only a slight increase in the accuracy of parent/guardian perception of their child's weight status after the intervention. A total of 700 parents/guardians of the selected kindergarten children returned the pre- intervention survey with the weight status question answered. A total of $72 \%$ (505) of the pre-survey respondents accurately described their child's weight status as overweight, at risk of overweight, about the right weight, or underweight. A total of 592 parents/guardians of the selected kindergarten children answered the weight status question and returned the postintervention survey. A total of $75 \%$ (443) of these post-survey respondents accurately described their child as overweight, at risk of overweight, about the right weight, or underweight on the post-intervention survey.

For the pre-intervention survey, $100 \%$ (26) of the parents/guardians of overweight children accurately described their child as such. Of the parents/guardians of normal weight children, $80 \%$ (470) described their child as about the right weight.

The perceptions of parents/guardians of at risk of overweight and underweight children were 
not as accurate. A total of $10 \%$ (2) of the parents/guardians of at risk of overweight children accurately described their child as at risk. A total of $11 \%$ (7) of parents/guardians accurately described their child as underweight. This is exemplified in Figure 2.

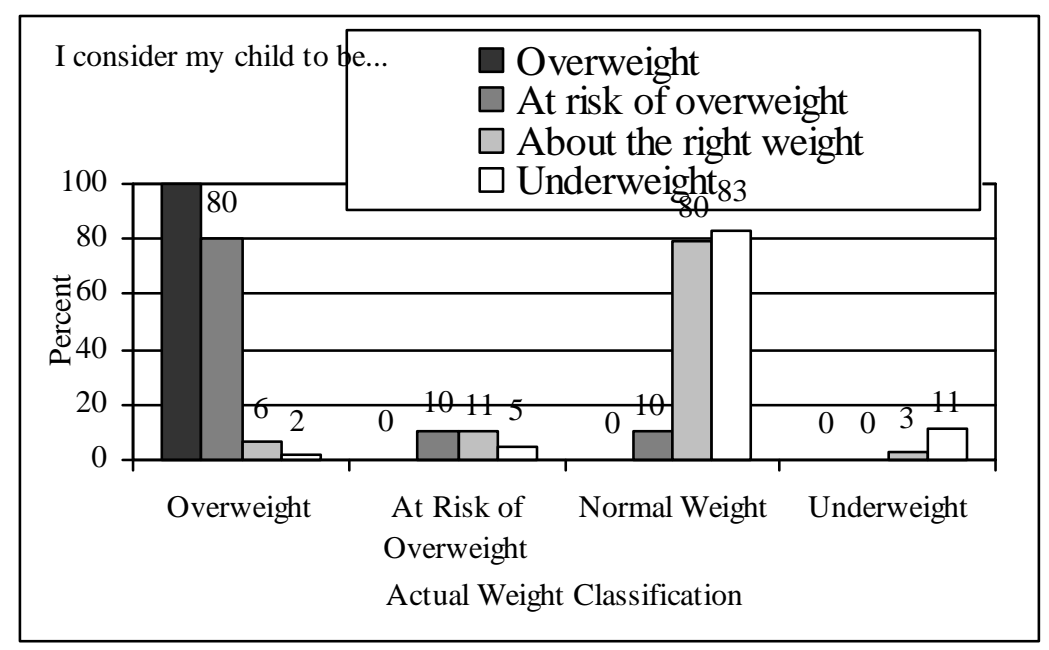

Figure 2

Weight Status Question of the Pre-Intervention Survey and BMI Results

As in the pre-intervention survey, $100 \%$ (20) of the post-intervention survey respondents whose child was overweight accurately identified their child's weight status. Also, 80\% (398) of the post-intervention respondents indicated that they perceived their child as about the right weight, when their child actually was normal weight, compared to pre-intervention survey results.

The perceptions of parents/guardians of at-risk overweight and underweight children increased after the intervention. A total of $47 \%$ (14) of parents/guardians accurately described their atrisk overweight child. A total of $23 \%$ (11) of parents/guardians of underweight children accurately described their child as underweight. The weight status question of the postintervention survey compared to the child's actual BMI is illustrated in Figure 3.

The largest variation in changes of perception occurred in the borderline categories of at risk of overweight and underweight. On the preintervention survey, $10 \%$ (2) of the survey respondents accurately described their child as at risk of overweight. This number increased to $47 \%$ (14) on the post- intervention survey. A total of $11 \%$ (7) of survey respondents accurately described their child's weight status.

There was not as much change with parents/guardians of children in the more definitive categories of overweight and normal weight. On the pre- and post- intervention survey $100 \%$ of parent/guardians of overweight children accurately described their child's weight status. For parents/guardians of normal weight children, $80 \% \quad(470)$ on the preintervention survey and $81 \%$ (398) on the postintervention survey accurately described their child.

This demonstrates that the intervention was more effective with parents/guardians of children in the at risk of overweight or underweight categories. However, a larger sample size is needed to determine if these findings are accurate. 


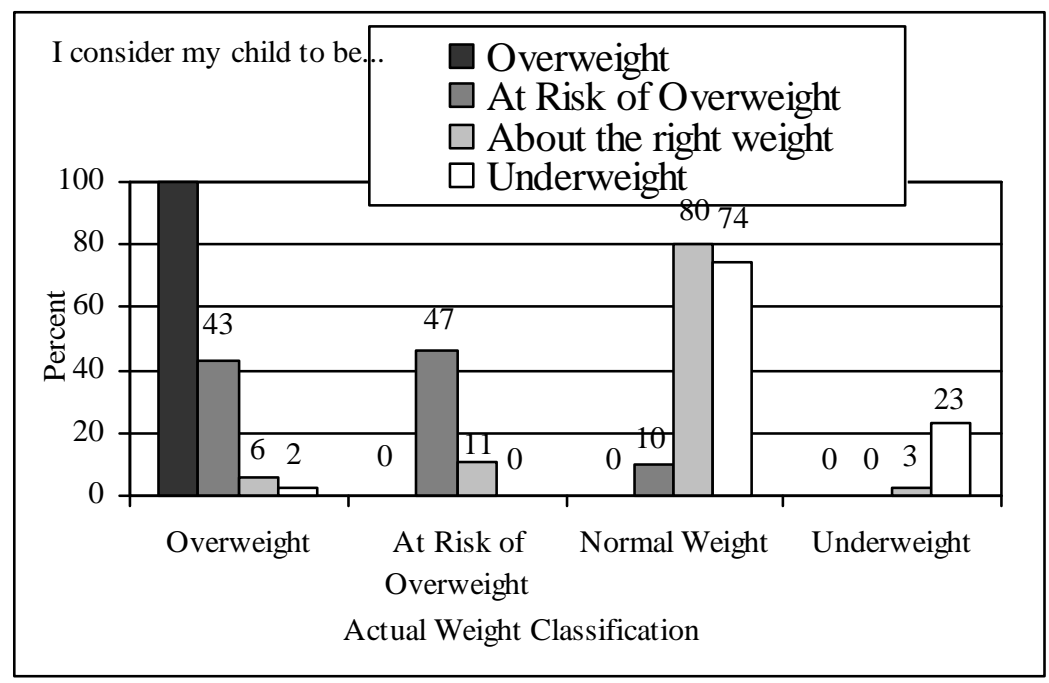

Figure 3

Weight Status Question of the Post-Intervention Survey and BMI Results

\section{Discussion}

It was found that an intervention based solely on literature was not an effective modifier for parents/guardians of overweight and normal weight children. The intervention was more effective in those with at risk of overweight or underweight children. This is interesting in that the parents of children in the more definitive category were not as easily persuaded by the intervention. The majority of parents/guardians of overweight and normal weight children were able to accurately describe their child's weight status, which may be an explanation as to why these parents/guardians were not as affected by the intervention.

It could be a possibility that parents/guardians of children in the more gray areas of at risk of overweight or underweight realize that there child may have a problem and is more apt to taking steps to correct it. For those that fell into the at risk of overweight category, this is a time when their child is not yet labeled "overweight," which may give the parent some motivation in changing their child's habits before it is "too late." For those parents/guardians of underweight children, their child's health is also considered at risk, which is also a motivator in initiating behavior change.

\section{Conclusions}

The study population accurately reflected the state of New Mexico as a whole. The participating districts were scattered across the state and were not concentrated in any one area. BMI's were collected on 1,480 kindergarten children. Based upon the findings of this study, there was only a slight increase in the accuracy of parent/guardian perception of their child's weight status after the intervention, from $72 \%$ pre-intervention and $75 \%$ post-intervention. The largest change in perceptions occurred within the at risk of overweight category, from $10 \%$ accuracy on the pre-intervention survey to $47 \%$ on the post-intervention survey. The next largest change occurred in the underweight category, from $11 \%$ accuracy on the pre-intervention survey to $23 \%$ on the post-intervention survey.

This study was a seminal attempt to obtain information regarding childhood obesity in the state of New Mexico, particularly among kindergarten children. The potential to build on the foundation established here is significant. A few areas of investigation are offered as recommendations for future research: 1) the intervention should include more than just literature, meeting and working with the parents/guardians in person, or on a more 
individualized basis, would increase the effectiveness of the intervention; 2) Health Educators can use this data to develop more sophisticated, tailored programs to impact weight, physical activity, fitness level, and diet; and 3) involve schools in interventions as they are in close contact with children and their families.

\section{References}

American Academy of Family Physicians. (2005). Obesity and children: Helping your child keep a healthy weight. Retrieved May 31, 2006, from http://www.familydoctor.org

Birch, L. L., \& Davison, K. K. (2001). Family environmental factors influencing the developing behavioral controls of food intake and childhood overweight. Pediatric Clinics of North America, 48, 893-907.

Bray, G. A. (2004). Medical consequences of obesity. The Journal of Clinical Endocrinology \& Metabolism, 89, 2583-2589.

Bray, G. A., \& Bellanger, T. (2006). Epidemiology, trends, and morbidities of obesity and the metabolic syndrome. Endocrine, 29, 109-117.

Centers for Disease Control and Prevention. (2005). Using the BMI-for-age growth charts. Retrieved April 7, 2006, from http://www.cdc.gov/nccdphp/dnpa/growthcharts/training/modules/module1/text/module1print.pdf

Centers for Disease Control and Prevention. (2006). BMI-body mass index: About BMI for children and teens. Retrieved March 31, 2006, from http://www.cdc.gov/nccdphp/dnpa/bmi/childrens_BMI/about_childrens_BMI.htm

Cooney, K. A., \& Gruber, S. B. (2005). Hyperglycemia, obesity, and cancer risks on the horizon. Journal of the American Medical Association, 293, 235-236.

Daniels, S. R., Khoury, P. R., \& Morrison, J. A. (1997). The utility of body mass index as a measure of body fatness in children and adolescents: Differences by race and gender. Pediatrics, 99, 804-807.

Dietz, W. H. (1998). Health consequences of obesity in youth: Childhood predictors of adult disease. Pediatrics, 101, 518-525.

Dietz, W. H. (2005). The burden of obesity in the United States: A problem of massive proportions. Centers for Disease Control and Prevention Chronic Disease Notes \& Reports, 17(2), 1-9.

Dietz, W. H., \& Bellizzi, M. C. (1999). Introduction: The use of body mass index to assess obesity in children. American Journal of Clinical Nutrition, 70, 123S-125S.

Fisher, F. O., \& Birch, L. L. (2002). Eating in the absence of hunger and overweight in girls from 5 to 7 years of age. American Journal of Clinical Nutrition, 76, 226-231.

Flegal, K. M. (2005). Epidemiological aspects of overweight and obesity in the United States. Psychology \& Behavior, 86, 599-602.

Flegal, K. M., Ogden, C. L., Wei, R., Kuczmarski, R. L., \& Johnson, C. L. (2001). Prevalence of overweight in US children: Comparison of US growth charts from the Centers for Disease Control and Prevention with other reference values for body mass index. The American Journal of Clinical Nutrition, 73, 1086-1093.

Freedman, D. S., Dietz, W. H., Srinivasan, S. R., \& Berenson, G. S. (1999). The relation of overweight and cardiovascular risk factors among children and adolescents: The Bogalusa heart study. Pediatrics, 103, 1175-1182.

Glanz, K., Rimer, B. K., \& Lewis, F. M. (2002). Health behavior and health education: theory, research, and practice. San Francisco: Jossey-Bass.

Kuczmarski, R. J., Ogden, C. L., Guo, S. S., Grummer-Strawn, L. M., Flegal, K. M., Mei, Z. et al. (2002). 2000 CDC growth charts for the United States: Methods and development. Vital and Health Statistics, 246(11), 1-190. 
Mandabach, L., \& Roth-Edwards, L. (2005). BMI report. Unpublished manuscript, New Mexico Department of Health.

McGarvey, E., Keller, A., Forrester, M., Williams, E., Seward, D., \& Suttle, D. (2004). Feasibility and benefits of a parent-focused preschool child obesity intervention. American Journal of Public Health, 94, 1490-1495.

Must, A., \& Strauss, R. S. (1999). Risks and consequences of childhood and adolescent obesity. International Journal of Obesity, 23 (Suppl 2), S2-S11.

National Center for Chronic Disease Prevention and Health Promotion, Centers for Disease Control and Prevention. (2004). Fact sheet-actual causes of death in the United States, 2000. Retrieved June 13, 2006, from http://www.cdc.gov/hccdphp/factsheets/death_causes2000.htm

National Center for Health Statistics, Centers for Disease Control and Prevention. (2004). Health, United States, 2004, with chartbook on trends in the health of Americans. Hyattsville, MD: Author.

National Center for Health Statistics, Centers for Disease Control and Prevention. (1994). Plan and operation of the third National Health and Nutrition Examination Survey, 1988-94. Retrieved July 6, 2006, from http://www.cdc.gov/nchs/data/series/sr_01/sr01_032.pdf

National Institute for Health Care Management Foundation. (2004). Obesity in young children: Impact and intervention. Retrieved January 25, 2006, from http://www.nihcm.org/OYCbrief.pdf

National Institute of Diabetes and Digestive and Kidney Diseases. Weight Control Information Network. (2004a). Healthy eating \& physical activity across your lifespan: Helping your child. Retrieved May 31, 2006, from http://www.niddk.nih.gov/health/nutrit/nutrit.htm

National Institute of Diabetes and Digestive and Kidney Diseases. Weight Control Information Network. (2004b). Helping your overweight child. Retrieved May 31, 2006, from http://www.niddk.nih.gov/health/nutrit/nutrit/htm

New Mexico Public Education Department. (2006). New Mexico schools locator. Retrieved June 5, 2006, from http://www.ped.state.nm.us/districts/index.html

Ogden, C. L. (2004, Summer). Defining overweight in children using growth charts. Maryland Medicine, 19-21.

Ogden, C. L., Carroll, M. D., \& Flegal, K. M. (2003). Epidemiologic trends in overweight and obesity. Endocrinology and Metabolism Clinics of North America, 32, 741-760.

Ogden, C. L., Flegal, K. M., Carroll, M. D., \& Johnson, C. L. (2002). Prevalence and trends in overweight among US children and adolescents, 1999-2000. Journal of the American Medical Association, 288, 1728-1732.

Ogden, C. L., \& Tabak, C. J. (2005, September 2). Children and teens told by doctors that they were overweight. Morbidity and Mortality Weekly, 54, 848-849.

Pietrobelli, A., Faith, M. S., Allison, D. B., Gallagher, D., Chiumello, G., \& Heymsfield, S. B. (1998). Body mass index as a measure of adiposity among children and adolescents: A validation study. The Journal of Pediatrics, 132, 204-210.

Polk, S. L. (2005). Definitions and demographics of obesity: Diagnosis and risk factors. Anesthesiology Clinics of North America, 23, 397-403.

Ressel, G. W. (2003). AHA releases scientific statement on cardiovascular health in childhood. American Family Physician, 67(3).

Rich, S. S., DiMarco, N. M., Huettig, C., Essery, E. V., Andersson, E., \& Sanborn, C. F. (2005). Perceptions of health status and play activities in parents of overweight Hispanic toddlers and preschoolers. Family \& Community Health, 28, 130-141.

Rimer, B. K., \& Glanz, K. (2005). Theory at a glance: A guide for health promotion practice. National Institute of Health, 13-14.

Ritchie, L. D., Welk, G., Styne, D., Gerstein, D. E., \& Crawford, P. B. (2005). Family environment and pediatric overweight: what is a parent to do? American Dietetic Association, 105(5), S70-S79.

Rosenstock, I. M. (1974). Historical origins of the Health Belief Model. In M. H. Becker (Ed.), The Health belief model and personal health behavior. Thorofare, NJ: Charles B. Slack, Inc. 
Rubenstein, A. H. (2005). Obesity: A modern epidemic. Transactions of the American Clinical and Climatological Association, 116, 103-111.

Sturm, R. (2005). Childhood obesity-what we can learn from existing data on societal trends, Part 1. Preventing Chronic Disease, 2(1).

United States Department of Agriculture. (2002). 10 steps for parents: Make physical activity easy. Retrieved May 31, 2006, from http://www.fns.usda.gov/

\title{
Acknowledgements
}

Author Amanda Jones received the Master of Public Health from New Mexico State University in December 2006.

\author{
Author Information \\ Amanda Jones, M.P.H.* \\ 610 Cline Road, Mesilla Park, NM 88047 \\ Ph. 505-571-0883 \\ Fax.: 505-382-7277 \\ E-Mail: amandaj_21@hotmail.com \\ Thesis Committee Chair: \\ Susan C. Forster-Cox, PhD., M.P.H., C.H.E.S. \\ Assistant Professor \\ New Mexico State University \\ Department of Health Sciences \\ P. O. Box 30001, MSC 3HLS \\ Las Cruces, NM 88001-8001 \\ Ph.: 505-646-2183 \\ Fax.: 505-646-4343 \\ E-Mail: sforster@nmsu.edu \\ * corresponding author
}

